\title{
Concientización y criticismo. Aportaciones de Raymond Williams y Paulo Freire a la educación de personas adultas
}

\author{
Conscientisation and criticism. Raymond Williams and Paulo Freire's contributions \\ to adult education
}

\author{
Emilio Lucio-Villegas \\ e-mail: elucio@,us.es \\ Universidad de Sevilla, España
}

\section{Resumen}

1921 marca el centenario del nacimiento de Paulo Freire, y también del pensador galés Raymond Williams. No consta que se conocieran, aunque quizás tuvieron alguna noticia de la obra respectiva. Vivieron en contextos radicalmente diferentes y con preocupaciones intelectuales también diferentes, pero el pensamiento de ambos presenta puntos en común muy interesantes: la importancia de la cultura, la insistencia en una educación de personas adultas que sea útil a la emancipación de las personas y las comunidades, la construcción de una sociedad democrática o el papel de las personas educadoras, entre otros. El artículo no pretende explorar posibles conexiones entre el pensamiento de estos dos autores, aunque ambos han tenido una influencia importante en la educación de personas adultas durante el siglo XX, que perdura a lo largo del XXI. Lo que pretendo en el texto es reflexionar sobre algunas de sus ideas que nos permitan resistir los embates del neoliberalismo presente en las políticas y las prácticas del aprendizaje a lo largo de la vida, y nos guíen en la senda de construir una sociedad y una educación más justas, solidarias y democráticas.

Palabras clave: concientización; criticismo; cultura; emancipación; persona educadora.

\begin{abstract}
1921 is the year of the centenary of Paulo Freire's birth, but also is the centenary of the birth of the Welsh thinker Raymond Williams. There is no proof that they personally knew each other, but perhaps they knew each other's work. They lived in radically different contexts, and with different intellectual worries. But their ideas have some very interesting common points: the importance of culture, the role of the educator, the insistence on the need for adult education that aids the emancipation of individuals and communities, and the building of a democratic society, among others. The article does not aspire to explore possible connections between the thoughts of both authors, even though they have been an important influence in adult education in the 20th century, that remains in the $21 \mathrm{st}$. What I would like to do in this paper is to reflect about some of their contributions that help us resist the battering of neoliberalism found in the policies and practices of Lifelong Learning. Their ideas also guide us on the path to building a fairer, more solidary and democratic society and an education.
\end{abstract}

Keywords: conscientisation; criticism; culture; emancipation; educator.

Cómo referenciar este artículo / How to reference this article:

Lucio-Villegas, E. (2021). Concientización y criticismo. Aportaciones de Raymond Williams y Paulo Freire a la educación de personas adultas. Tendencias Pedagógicas, 38, pp. 57-67. doi: 10.15366.tp2021.38.006. 


\section{Introducción}

Dos mil veintiuno señala el centenario del nacimiento de Paulo Freire. Es un buen momento para celebrar «un trabajo que motiva a la liberación [...] un legado tan poderoso, que no importa si tiene algún error» (Hooks, 2003, p. 196). Es un momento también para reflexionar sobre las aportaciones del pensador brasileño a la educación y más específicamente a la de personas adultas, sobre el sentido de la educación liberadora y la capacidad y la posibilidad de pensar, imaginar y practicar la educación lejos del pensamiento dominante del aprendizaje a lo largo de la vida que encorseta la educación en la escuela y limita los fines de la educación a la empleabilidad de las personas. Dos mil veintiuno es un año para celebrar, también, el centenario del nacimiento del pensador galés Raymond Williams, lo que debe darnos la oportunidad de reflexionar sobre sus aportaciones a la educación de personas adultas desde su propia práctica como educador y desde su compromiso con una sociedad democrática.

Uno de los problemas que, en ocasiones, puede encontrarse es el hecho de que la figura de Freire - mejor dicho, el uso que a veces se hace de la figura de Freire- ha ensombrecido, cuando no simplemente invisibilizado, las contribuciones de otros pensadores. En nuestro ámbito, este es el caso de Raymond Williams o de otros como Ettore Gelpi, sin prácticamente presencia en la literatura sobre educación de personas adultas en nuestro entorno. Ello contrasta con la transmisión mecánica y mesiánica de la obra de Freire. Esta transmisión oculta, en más ocasiones de las que podría gustarnos, simplemente el afán de mantener posiciones de poder en el mundo de la academia o de los movimientos sociales.

En el artículo no pretendo hacer una comparación del pensamiento de ambos autores - Freire y Williams - porque creo que no tiene sentido intentar comparar o conectar artificialmente la obra de personas que vivieron en contextos — de todo tipo— diferentes. Además, me parece que determinadas comparaciones o relaciones que se vienen estableciendo entre Freire y otros autores o autoras en ocasiones creo que bastante artificiosas - son tremendamente oportunistas y fomentan la creación de un nuevo pensamiento totalizante sobre el autor brasileño, con una absoluta ausencia de crítica.

Lo que me parece importante, y me gustaría hacer en este texto, es presentar algunas contribuciones nucleadas alrededor de temas comunes para los dos, y para muchas de las personas que trabajan (trabajamos), de alguna forma, en la educación de personas adultas. Creo que hay elementos comunes que están en las preocupaciones de las personas que desarrollan su labor en este ámbito, que pueden ayudarnos a reflexionar sobre el sentido de la educación y de la educación de personas adultas en un entorno marcado ahora por la COVID-19, que solo ha venido a profundizar los desequilibrios y las desigualdades en todos los ámbitos.

Más aun cuando nos encontramos situados en el marco asfixiante del aprendizaje a lo largo de la vida y su discurso deshumanizador que propone que las únicas realidades de las personas se encuentran ligadas al trabajo —o a formar parte del «ejército industrial de reserva»—, y no a la participación en una sociedad democrática — cada vez más amenazada —, a la construcción de vínculos de cooperación y solidaridad comunitaria y al pleno desarrollo de las capacidades de las personas para interpretar y transformar su entorno en colaboración con las otras.

Algunas de estas preocupaciones comunes a los dos creo que pueden resumirse en las siguientes: i) el papel de la cultura, ii) el debate sobre los fines de la educación: la concientización para Freire o el criticismo para Williams, entre otras finalidades, y iii) el rol de la persona educadora. Lo que quiero destacar, para terminar esta introducción, es cómo el pensamiento de estos autores, en estos temas y en otros, está marcado por la búsqueda constante de la equidad, la justicia social y la construcción de la ciudadanía, y nos ayudan a resistir la vorágine de una educación que solo aspira a mantener las relaciones de desigualdad. Freire y Williams ayudan a la construcción de un pensamiento contrahegemónico (Gramsci, 1974) con el que enfrentar las tendencias educativas y sociales dominantes.

A partir de ahora voy a hacer un repaso muy breve a la biografía de ambos, y luego me centraré en los temas que he señalado más arriba.

\section{Apuntes biográficos}

Raymond Williams nació en Pandy, País de Gales, el 31 de agosto de 1921. Asistió a escuelas en Gales y más tarde fue enviado a estudiar en la Universidad de Cambridge. Siempre recordó y subrayó el 
hecho de que la enseñanza era impartida en inglés y se castigaba a quienes usaban el galés para comunicarse en la escuela, lo que atribuyó a una forma de imperialismo cultural. Es posible que esta experiencia le hiciera concebir la educación como una práctica cultural, una de sus aportaciones imprescindibles a la educación de personas adultas. Participó en la II Guerra Mundial, pero se declaró objetor para no participar en la de Corea, que entendió como una imperialista (Smith, 2008). Fue tutor de la Workers Educational Association (WEA, por sus siglas en inglés) donde desarrolló su práctica como educador de personas adultas. Más tarde se incorporó a la Universidad de Cambridge como catedrático de Drama Moderno. Fue uno de los fundadores de la New Left Review, y junto a E. P. Thompson y R. Hoggart fue uno de los «creadores» de los estudios culturales. También escribió novelas, la más famosas de todas, Border Country ([1960] 2013), es considerada una especie de autobiografía. Entre sus obras destacan Cultura y Sociedad (1960) y La larga revolución (1965).

Raymond Williams no es, generalmente, reconocido como un autor ligado a la educación de personas adultas. No obstante, siempre concibió su práctica en la WEA como una actividad educativa dirigida a personas adultas en la que era imprescindible «reinventar constantemente la tarea educativa» (Beltrán, 2004, p. 9). Una de sus ideas fundamentales es que la educación debe ser concebida como una práctica cultural que se constituye a partir de la experiencia de vida de las personas, lo que entronca con las concepciones emancipadoras de la educación de personas adultas. Aun cuando es un autor no reconocido, en nuestro entorno, como un pensador relacionado con la educación de personas adultas, su influencia en otros ámbitos geográficos es considerable, y me parece muy importante rescatar su pensamiento. Para él, la educación «se fundamenta en el reconocimiento de la equidad de las personas» (1959, p. 124). Raymond Williams falleció el 26 de enero de 1988.

Paulo Freire nació el 19 de septiembre de 1921 en la ciudad de Recife, en Brasil. Su madre, y parece ser una influencia importante, era una persona profundamente religiosa. Tras la crisis de 1929 y el posterior fallecimiento de su padre, la familia empobreció y tuvo que mudarse a un lugar donde la vivienda y la vida eran más baratas: Jaboatão, cerca de Recife. Freire estudió Derecho, comenzó a trabajar en el Servicio Social de la Industria y luego en la Universidad de Recife, donde fue responsable del Servicio de Extensión Cultural. A principios de los años 60 del siglo pasado inició diversas experiencias de alfabetización en Brasil. Estas experiencias son fundamentales como germen para sus primeros trabajos y, principalmente, para Pedagogía del Oprimido. Fue nombrado coordinador del Programa Nacional de Alfabetización, que abarcaba todo Brasil y que se vería frustrado por el golpe de estado militar de 1964.

Tras el golpe, el exilio lo lleva a Bolivia, Chile, Estados Unidos y, finalmente, a Ginebra para trabajar en el Departamento de Educación del Consejo Mundial de las Iglesias. Esta época es fundamental para conocer y entender el proceso de reconocimiento internacional de la figura de Freire. Su trabajo le permitió viajar y entrar en contacto con figuras clave en los procesos de descolonización, como Frantz Fanón o Amilcar Cabral, entre otros. Durante el exilio, fundará el Instituto de Acción Cultural (IDAC), que se convertirá en un referente de la acción cultural y la educación.

Freire regresa a Brasil en 1980 para trabajar en la Universidad Católica de São Paulo (PUC/SP) y en la Universidad Estatal de Campinas (UNICAMP). Ejerció como responsable del Departamento de Educación de la Prefectura de São Paulo entre 1989 y 1991. Fue uno de los fundadores del Partido de los Trabajadores de Brasil, y del Instituto Paulo Freire de Brasil, instaurado en 1992. En este tiempo, Freire reescribe una parte importante de sus ideas y elementos conceptuales. Paulo Freire falleció el 2 de mayo de 1997. Entre sus obras destacan Pedagogía del Oprimido (1985) ${ }^{1}$ —el texto pedagógico traducido a más idiomas-, o La educación como práctica de la libertad (1986).

\section{Cultura}

Uno de los elementos centrales de la obra de Raymond Williams es el referido a la cultura. La cultura entendida, además, como un instrumento de construcción y mantenimiento de una sociedad democrática. El texto fundamental, en esta dirección, es, posiblemente, La larga revolución (Williams, 1965)².

\footnotetext{
${ }^{1}$ El manuscrito fue finalizado en 1968 y la primera edición impresa fue publicada en 1970 en inglés.

2 Originalmente publicado en 1961.
} 
Como ya señalé antes, Williams consideraba la educación de personas adultas como una práctica y un proceso de transformación cultural. Consideraba que la cultura debe ser entendida en plural, como culturas. Citando a Herder, indica:

Es entonces [...] necesario hablar de «culturas» en plural: las específicas y variables culturas de diferentes naciones y períodos, pero también las específicas y variables culturas de grupos sociales y económicos dentro de una nación (1985, p. 89, entrecomillado en el original).

Es muy importante la conexión entre cultura y clase social y también el abandono de las culturas consideradas minoritarias o subyugadas como el caso que él mismo había vivido durante su escolaridad con el abandono y la marginación del gaélico como idioma escolar y de construcción y transmisión de conocimiento.

Por otro lado, las culturas están ligadas a los momentos históricos y conectan con determinadas formaciones sociales que son específicas en situaciones históricas determinadas, aspecto que fundamenta los «estudios culturales» como un abordaje contextualizado de los movimientos culturales en cada momento histórico. Son estilos de vida que abarcan elementos materiales, intelectuales, espirituales. Es «un modo de interpretación de nuestra experiencia común, y, con esta nueva interpretación, cambiarla» (William, 1960, p. XVIII).

Utilizando un abordaje marxista, diferenció entre las culturas como producciones materiales y las culturas como estructuras simbólicas. Estas estructuras simbólicas son las que dan sentido a plantearnos una educación que permita participar de esas culturas comunes, y al mismo tiempo refinar las experiencias individuales. Más adelante me referiré al concepto de criticismo. Por ahora basta con considerar que la cultura debe contrastarse y superar lo que Gramsci denominó folclore como una forma que no es emancipadora, sino opresora. En ese sentido, Gramsci había establecido una diferencia entre alta y baja cultura y consideraba que la baja cultura podía adoptar la forma de dominación, a causa de su no sistemática y contradictoria estructura, y su carácter políticamente desorganizado (Díaz Salazar, 1991).

En cualquier caso, para Williams, «La cultura popular [...] presenta el conocimiento por caminos generalmente accesibles» $(1985$, p. 23). Es también un modo de vida, algo que es común en las personas.

Finalmente, puede decirse que Williams consideró tres categorías de uso del concepto de cultura. Por un lado, la descripción de un proceso de desarrollo intelectual, espiritual y estético. En segundo lugar, un modo de vida particular, por último, al hablar de un trabajo especializado y de actividades artísticas. El uso que nos interesa especialmente es el segundo: la consideración de la cultura como un modo de vida, una estructura simbólica, común a las personas que viven en comunidad. Un elemento en constante formación y reformulación que debe llevar a la creación de una educada democracia participativa (Morgan, 1997). En definitiva, como señala Cole (2008, s/p): «La lección más importante de Raymond Williams para los educadores es el profundo y continuo énfasis que hace sobre la cultura como un elemento constitutivo de la sociedad, y como un medio potencial para la transformación social»

Para Freire, la cultura se enmarca en el proceso de humanización de la persona. Ese proceso de humanización supone, entre otras cosas, que las personas pueden escapar de la que denomina Cultura del Silencio: formas de dominación que les impiden expresarse por sí mismas. El concepto de humanización está presente desde el principio de su obra. De hecho, es el núcleo central de La educación como práctica de la libertad (Freire, 1986). El proceso de adquisición de una cultura y el de humanización son paralelos: es la introducción en el mundo de una cultura lo que hace que la persona se desarrolle como tal. Al referirse a los procesos de codificación/decodificación, indica:

Reconocidos, después de la primera situación, los dos mundos —el de la naturaleza y el de la cultura y el papel del hombre [sic] en esos dos mundos - se suceden otras situaciones en las que se aclara y amplia la comprensión del dominio cultural. (Freire, 1986, p. 107)

Por tanto, la esencia de la cultura para Freire está relacionada con poder despegarse de la naturaleza - en el sentido de no confundirse con ella. La construcción de la cultura permite que la persona «se reconoce como sujeto que, al interferir y transformar los elementos que están a su disposición en la 
naturaleza y en el mundo que lo rodea, produce cultura» (Osowski, 2015, p. 127). La cultura, entonces, convierte a las personas en seres sociales.

Ya he señalado un poco más arriba que la cultura del silencio es la imposibilidad de las personas y las comunidades de expresar su propio pensamiento e ideas. Esto implica que existen unas culturas dominantes y unas culturas subordinadas. La cultura del silencio es una subordinada generada por estructuras sociales opresoras. Es una cultura que se transmite, y se mantiene, en la escuela, entre otros lugares.

Junto a esta idea general de introducción en una cultura como proceso de humanización, hay algunos otros elementos que es interesante analizar. Por un lado, la expresión cultural. Emerger de la cultura del silencio para decir la palabra implica que la construcción de formas de expresión de la propia cultura debe ser una de las finalidades de los procesos de aprendizaje. Y esto supone, como señala Freire, que el aprendizaje de la lectura y la escritura «introduce al analfabeto [sic] en el mundo comunicativo de la escritura [...], partiendo de aquí el analfabeto puede cambiar sus capacidades previas. Pueden descubrirse críticamente como creadores de cultura» (1986, pp. 105-106).

\section{Más allá de la cultura: la construcción del sentido crítico y la conciencia}

La cultura es un elemento central en la concepción de la educación de personas adultas que proponen tanto Williams como Freire. Para el primero, como ya señalé, la cultura es algo común, un estilo de vida. Para Freire, la cultura es el proceso por el que la persona se convierte en tal. Para ambos, la cultura es colectiva, las personas la van construyendo en sus interacciones sociales y, en ningún caso, puede ser abordada de forma acrítica. Freire señalaba cómo el opresor coloniza la mente de la persona oprimida, de la misma forma que Williams reflexionaba sobre la forma de colonización que suponía la prohibición de utilizar el gaélico en la escuela. Represiones que hemos vivido muchos andaluces de mi generación y que vuelven a aparecer con las críticas de los sectores más reaccionarios de la sociedad al habla de la ministra María Jesús Montero.

Unos de los elementos que más ha colaborado en convertir la cultura de las personas en un elemento de contemplación sin valor de significación o de reivindicación ha sido el turismo. El caso del flamenco y de las canciones populares andaluzas es muy claro. Cuando se canta «un mozo con dinero "la ha enamorao", la separó de ti..., se la ha "llevado"»", la letra parece referirse al tópico de un triángulo amoroso - o una traición- y no a las relaciones de semiesclavitud entre las personas que trabajan en las grandes explotaciones agrícolas del campo andaluz - migrantes o no- y las personas que detentan la propiedad de esas explotaciones y amenazan a la Ministra de Trabajo por enviar inspectores para investigar unas condiciones de trabajo que son, en algunos casos, más cercanas a la Edad Media que al siglo XXI. El cine - un arte y una expresión de la cultura popular por el que R. Williams siempre tuvo gran interés - recogió este tipo de relaciones en la magistral Los Santos Inocentes.

A partir de aquí, parece que la educación de personas adultas debería ir más allá de, simplemente, santificar determinadas manifestaciones de la cultura popular y someterla a análisis y crítica, construyendo un sentido estético y situando a las personas en su contexto cultural como punto de partida para edificar otras visiones y perfeccionar la forma en que la gente asume una conciencia nueva de su cultura y puede construirla y reconstruirla sin las alienaciones que provocan la presencia y las presiones de las/los opresoras/os.

Raymond Williams (1985) utiliza el término criticismo derivándolo de la crítica literaria y despojándolo de su sentido negativo. La crítica es una respuesta natural que el autor relaciona con el sentido de caminar desde la censura, o la crítica negativa, a la construcción del gusto y lo que denomina una persona cultivada. No se trata, afirma Williams, de buscar algo que falta. La idea de criticismo implica construir juicios conscientes que se encuentran ligados a las situaciones y a los contextos. Señala:

Lo que necesita comprenderse es la especificidad de la respuesta, que no es un «juicio» abstracto, donde deben incluirse, a menudo de forma necesaria, respuestas positivas o negativas,

\footnotetext{
${ }^{3}$ Letra de una sevillana compuesta por Luis y Carlos Baras en 1973. https://www.rocio.com/sevillana/la-novia-del-campesino/ (Recuperado el 7 de enero de 2021).
} 
una práctica definida, en activa y compleja relación con su situación y su contexto (Williams, 1985, p. 86, entrecomillado en el original).

En resumen, la educación de personas adultas debe ayudar a las personas a construir juicios que les permitan poner en cuestión las visiones que les han sido transmitidas de forma acrítica y se han asentado como verdades indiscutibles que fundamentan y orientan la vida cotidiana de las personas. Freire lo llamó concientización.

Este es, quizás, el más controvertido de los conceptos en el conjunto de la obra de Paulo Freire. Dejó de usarlo durante bastante tiempo porque consideró que era comprendido solo en un sentido epistemológico: un hombre o una mujer pueden llegar a ser conscientes de su opresión de forma intelectual, y pueden construir conocimientos sobre esta situación, obviando las prácticas sociales que están en la base del proceso. Como señala Torres (2007),

Paulo Freire adoptó la noción de conscientización en su trabajo, y lanzó un gran reto a la educación autoritaria y bancaria, pero abandonó su uso cuando vio que se estaba usando como mentira para tiznar la implementación de la racionalidad instrumental bajo el disfraz de la educación radical (p. 216, cursiva en el original).

Kirkwood y Kirkwood (2007) definen la concientización como

el proceso mediante el que las personas son estimuladas y animadas a explorar su realidad y su conciencia de ella de forma que la comprensión de la realidad y de su propia conciencia es cada vez más profunda, y comienza a comprometerse como praxis (p. 198, cursiva en el original).

El concepto de conciencia supone que la persona es un ser que existe en y con el mundo; y, sobre todo, que reflexiona sobre esta situación.

Mientras que el ser que simplemente vive no es capaz de reflexionar acerca de sí mismo y saberse viviendo en el mundo, el sujeto existente reflexiona acerca de su vida dentro del territorio mismo de la existencia y cuestiona su relación con el mundo (Freire, 1990, p. 86).

En este proceso, cada persona — siempre de forma colectiva a través del diálogo — se une con otras para poder transitar desde una conciencia mágica a una crítica. La concientización es un proceso y nunca un estado final. En ese camino Freire señala diferentes estadios: conciencia mágica, conciencia ingenua $y$, finalmente, conciencia crítica.

La conciencia mágica es propia de la persona considerada como un objeto y que se encuentra casi identificado con la naturaleza. Su conciencia es intransitiva. Se caracteriza porque proviene de una sociedad cerrada y considera las fuerzas de la naturaleza misteriosas e incontroladas y, por tanto, les rinde culto. En la conciencia mágica no hay percepción estructural de la realidad. Se genera una postura fatalista, de aceptación de los acontecimientos y de marginación ante la vida.

La conciencia ingenua se superpone a la realidad, los acontecimientos se viven ingenuamente. Se puede dividir entre conciencia ingenua intransitiva y conciencia ingenua transitiva. La intransitiva, propia de lo que Freire (1986) llamó sociedades cerradas, se caracterizaría por la simplicidad en la interpretación de los problemas, la supervaloración del tiempo pasado como mejor, la subestimación de la gente común y sus conocimientos, una cierta inclinación al gregarismo, las dificultades por aceptar los resultados de la investigación, y la utilización de una argumentación básicamente emocional. Considera fundamental acomodarse al presente, no practica el diálogo sino la polémica. Los datos que se captan son los que se encuentran dentro de la experiencia vivida. No se objetivan los hechos de la vida cotidiana, los acontecimientos se achacan a razones alejadas de la realidad objetiva.

Con la conciencia crítica las personas comienzan a construir sus propias visiones de la realidad y también van recuperando su propia cultura. Para Barreiro (1986), se caracteriza porque el examen de los problemas se realiza colectivamente por medio del diálogo, hay una mayor profundidad en el análisis de las situaciones, se reconoce que la realidad es cambiante, se construyen explicaciones causales, se verifican los hallazgos. Supone un acto de creación de conocimiento y es, por ello, una conciencia dinámica. 


\section{Las personas educadoras}

Aun cuando en España no existe una titulación relacionada con la educación de personas adultas lo que sería imprescindible para construir un campo de docencia e investigación específico- es necesario reflexionar sobre el papel de la persona educadora en escenarios que aspiran a explorar una educación emancipadora que ayude a la continua reconstrucción de la cultura y de los saberes que las personas construyen y mantienen.

El texto más interesante para conocer algunas de las ideas de Williams sobre el papel de las personas educadores es Carta abierta a los tutores de la WEA (Williams,1961). En ella comienza afirmando que su trabajo como educador de personas adultas «ha sido un buen trabajo, pero siempre, como para muchos tutores, ha sido más que un trabajo» (p. 222). Cree que ha sido más que un trabajo porque el mantenimiento de la educación de personas adultas garantiza «la organización de la justicia social, y de las instituciones de la democracia» (p. 223). La democracia, insiste Williams, solo puede desarrollarse en un marco donde las personas sean educadas, y la educación de personas adultas «defiende una educada democracia, no una nueva movilidad y una elite más variada» (p. 223).

Para R. Williams, la esencia de la relación educativa es el intercambio y la discusión.

He discutido D. H. Lawrence con mineros; he discutido métodos de argumentación con trabajadores de la construcción; discutido periódicos con jóvenes sindicalistas; sobre televisión con aprendices en proceso de aprendizaje [...] he aprendido tanto como he enseñado (Williams, 1961, p. 224).

La figura y el papel de la persona educadora en Freire ha sido muy discutida. Se llegó a afirmar que Freire había hecho desaparecer las diferencias entre educador y educando por considerarlos iguales en el proceso educativo. Nada más lejos de la realidad. Él mismo reconoce que «tiene que haber diferencias radicales entre un militante de izquierda y un militante de derecha en el uso que hagan del mismo proyector de diapositivas» (Freire, 1984, p. 45).

Uno de los textos donde es posible apreciar las preocupaciones freireanas sobre la persona educadora es, sin duda, Professora sim, tía não (Freire, 1997).

Para Freire, lo que la persona educadora hace deriva de los conocimientos que tiene y de cómo estos se van reevaluando para construir una práctica mejor. Todo ello sin olvidar las condiciones materiales de la escuela, del contexto escolar, de la comunidad donde las personas viven. También el propio contexto del aula, buscando respuesta a preguntas tales como: ¿cómo son los estudiantes?, ¿de dónde vienen?, ¿cómo reaccionan a la experiencia de la escuela?, ¿cómo se relacionan con sus compañeras y compañeros? Todo ello conlleva la asunción de la diversidad — no solo cultural— que se encuentra en un aula, y el respeto a esa diversidad y a las formas culturales y lingüísticas de las personas que se están educando.

Junto a ello, se encuentra la tensión entre práctica y teoría, que debe estar presente en el hecho de que «la formación permanente de las educadoras [sic], que implica la reflexión crítica sobre la práctica, se funda exactamente en esta dialéctica entre práctica y teoría» (Freire, 1997, p. 74). Más aun,

No puedo estar seguro de lo que hago si no sé cómo fundamentar científicamente mi acción, si no tengo, por lo menos, algunas ideas en torno de lo que hago, de por qué lo hago, y de para qué lo hago (Freire, 1997, p. 40).

En resumen, para Freire, en la labor docente hay un elemento de conocimiento didáctico y científico y otro elemento ético que tiene que ver con la construcción de los afectos que se producen en toda relación humana, integrando los conocimientos cotidianos en la experiencia escolar.

La experiencia de la comprensión será tanto más profunda cuanto más capaces seamos de asociar, nunca dicotomizar, los conceptos emergentes en la experiencia escolar a los que provienen del mundo de la cotidianeidad (Freire, 1997, p. 20, en cursiva en el original).

\section{Conclusiones}

Como ya he dicho al principio de estas líneas, no pretendo establecer ninguna comparación ni construir relaciones artificiales entre estos dos autores. No creo que sea posible hacerlo. Como indicaba 
Raymond Williams, al hablar de los estudios culturales debemos situar a cada autor, a cada autora, en el contexto social, político, económico, histórico o académico en el que se encuentran. Hacer esto nos permite comprender sus ideas y situarlas en un marco propio. Creo que los contextos de desarrollo del pensamiento de Freire y Williams son bastante diferentes y no admitirían, como ya insistí en la introducción, el establecimiento de relaciones oportunistas y bastante artificiales construidas en base a «juegos» académicos.

Lo que sí creo es que podemos reflexionar sobre las aportaciones de estos pensadores — $\sin$ los que, en mi opinión, no podemos imaginar un cierto enfoque de la educación de personas adultaspara enfrentarnos al pensamiento totalizador del aprendizaje a lo largo de la vida y su mensaje de que la persona es primariamente trabajadora y, secundariamente, consumidora y convertirla en una buena trabajadora y consumidora responsable son los fines de la educación. Creo que para resistir esta tendencia deshumanizadora de la vida y la educación Freire y Williams nos ofrecen aportaciones relevantes, desde sensibilidades similares.

La primera cuestión tiene que ver con los fines de la educación. Dewey ([1916] 1995) señalaba que los fines de la educación deben estar en la educación en sí misma, que no se deben buscar finalidades ajenas a ella. El aprendizaje a lo largo de la vida ha colocado los fines de la educación en lo que denomina «empleabilidad», la capacidad de poder acceder a un empleo — que es diferente de la seguridad de acceder a un empleo digno y estable- y presentarse en un mercado donde pueda estar disponible cuando sea requerido. Pero los fines de la educación deben ser otros. Para Freire, tenían que ver con aprender a decir la palabra, que era decir el mundo, comprender la realidad, tener una opinión propia y poder expresarla. Virginia Woolf ([1929] 2019) expresó con gran sensibilidad el sentido de esta propuesta freireana:

Y llegó la mayor liberación de todas, la libertad de pensar en las cosas como son. Aquel edificio, por ejemplo, ¿me gusta o no? ¿Es bello aquel cuadro o no? En mi opinión ¿este libro es bueno o malo? (p. 56)

Para Raymond Williams, la educación está intrínsecamente ligada a la construcción de una sociedad democrática.

\begin{abstract}
Si la persona es esencialmente un ser que aprende y se comunica, la única organización social adecuada a su naturaleza es la democracia participativa, en la que todos nosotros, como individuos únicos, aprendemos, comunicamos y gobernamos. Cualquier disminución, cualquier sistema restrictivo es, simplemente, un desperdicio de nuestros verdaderos recursos; dilapidar individuos, expulsándolos de un proceso de participación efectivo, es dañar nuestro auténtico proceso común. (Williams, 1965, p. 118)
\end{abstract}

Un segundo elemento que me gustaría destacar tiene que ver con la cultura. Yo creo que el trabajo sobre la cultura es el corazón de la educación de personas adultas. Como señala Geertz (1987), la cultura nos permite entender lo que ocurre a nuestro alrededor y darle un sentido, porque la cultura son un conjunto de

sistemas en interacción de signos interpretables... no es una entidad, algo a lo que puedan atribuirse de manera causal acontecimientos sociales, modos de conducta, instituciones o procesos sociales; la cultura es un contexto dentro del cual pueden describirse todos esos fenómenos de manera inteligible (p. 27).

Más arriba expliqué cómo, para Williams, la cultura es siempre plural. Ese canto a la diversidad es imprescindible en un momento en que el pensamiento hegemónico — también en el sistema educativo - se fundamenta en la presentación de un modelo al que debemos aspirar. No olvidemos el intento de crear un comisionado sobre el estilo de vida europeo o las constantes referencias a «nuestra» forma de vida, que hay que salvaguardar frente a «los otros».

Para Freire, la cultura era un elemento consustancial a la creación de la persona en comunidad. La cultura se produce, según esto, en la propias interacciones sociales que las personas van construyendo. La cultura del silencio también se construye dentro de la comunidad e intenta minimizar los vínculos comunitarios y sociales. Como señala Osowski (2015), 
La cultura del silencio es generada en estructuras opresoras en las cuales los hombres y las mujeres se someten a fuerzas condicionantes [...] colocadas como están en estructuras que las sumergen y las diluyen en el tiempo (p. 130, en cursiva en el original).

Es imprescindible, por tanto, la recuperación y el fortalecimiento de la vida comunitaria. Recuperar el concepto de comunidad — posiblemente la pandemia de la COVID-19 ha permitido recuperar un cierto sentido de comunidad y de solidaridad — frente al individualismo que emerge del pensamiento social y educativo dominante. No hay que olvidar que la comunidad implica «una particular cualidad en las relaciones» (Williams, 1985, p. 75), y que «existen nuevos modos de alienación y control, que previenen y han sido diseñados para impedir el desarrollo de una auténtica consciencia popular» (Williams, 1985, p. 196, en cursiva en el original).

\begin{abstract}
Insisto en la importancia de recuperar la diversidad, y considerar esta como un asunto que va más allá del ámbito lingüístico (Besalú, 2010). Para Gelpi (2004), aun cuando las diferencias debidas a la lengua, a la pertenencia étnica y a la religión son significativas, es necesario no olvidar otros elementos que constituyen otros tipos de diversidad: la edad, el sexo, el acceso a la formación y a la información, la relación con el mundo de la producción (la identidad, por ejemplo, de un desocupado no es la misma que la de un trabajador con empleo), el acceso a los cuidados médicos, el derecho a la retribución, el tipo de ambiente en el que se vive, el grado de libertad de movimientos que posee (el ciudadano libre de circular y el preso), el discapacitado, etc. Tales diferencias indican también la complejidad de la pertenencia de un determinado grupo o de un individuo a este conjunto de diversidades. (p. 57).
\end{abstract}

Como ya he dicho, el asunto de la cultura me parece fundamental y creo que una educación de personas adultas que aspire a la emancipación (Inglis, 1997) debe considerar este asunto como primordial. Pero el trabajo sobre la cultura debe ir más allá del reconocimiento de la cultura popular. Supone desbrozar los elementos alienadores que existen dentro de la cultura popular y denunciar la intrusión de las fuerzas que impiden el desarrollo de las personas.

Creo en la necesaria lucha económica de la clase obrera organizada. Creo que es la actividad más creativa en nuestra sociedad. Pero sé que hay un trabajo profundamente necesario que hacer con relación a los procesos de la hegemonía cultural misma. Creo que el sistema de significados y valores que ha generado la sociedad capitalista tiene que ser derrotado en general y en los detalles con los tipos de trabajo intelectual y educativo más constantes. Este es un proceso cultural que denominé la «larga revolución» y designándolo como la «larga revolución» subrayé que fue una lucha genuina parte de las necesarias batallas por la democracia y la victoria económica de la clase obrera organizada (Williams, en McIlroy, 1993, p. 308).

La noción gramsciana de hegemonía (cf. Gramsci, 1974, Williams, 1977) parece la conclusión natural a la reflexión sobre el papel de la cultura en la educación de personas adultas. La construcción de un modelo social, económico, ambiental y educativo alternativo se juega en la cultura, en la capacidad de construir imágenes y realidades diferentes. Superar el folclore como visión alienada - y construidade la cultura popular y reconstruir una que permita a las personas situarse en el mundo e interpretarlo es un objetivo indispensable de la educación de personas adultas.

Un último elemento en el que me gustaría detenerme tiene que ver con el papel de la persona educadora. Si se repasan los documentos de la Unión Europea referidos al aprendizaje a lo largo de la vida, puede apreciarse la desaparición de dos términos. Uno es el propio de educación, el segundo el de educador/a. Se habla de una persona que aconseja, de una persona practicante, pero nunca de una persona educadora.

Las aportaciones de Freire y Williams en esta dirección son especialmente relevantes para devolver la dignidad del trabajo educativo. Para Freire, la tarea docente tiene un elemento de conocimiento didáctico y científico y otro ético que tiene que ver con la construcción de los afectos que se producen en toda relación humana. Esta propuesta tiene que ver también con la idea de construir el sentido de dignidad y de la importancia de la tarea de educar.

Por su parte, Williams, desde su perspectiva y su experiencia como educador de personas adultas, planteó una propuesta metodológica en la que el educador potenciaba la compresión de los textos y que transitaba «desde la transmisión a la autodirección y participación» (McIlroy, 1993, p. 288). No menos importante aquí es también el hecho de considerar que los sentimientos — que provienen del 
contacto con las personas - tienen que estar presentes y conectarse con el trabajo académico e intelectual.

En ambos autores encontramos la imagen de una persona educadora que establece relaciones humanas con los participantes, que construye un sentido de dignidad profesional y busca establecer unas relaciones educativas diferentes que deben sustentarse en la justicia y la equidad (Finger y Asún 2001). En este año de centenarios, nuestro reto debe seguir siendo construir procesos educativos donde las personas reconozcan - y se reconozcan en - sus culturas, potencien su vida comunitaria —en un momento en que las interacciones sociales se encuentran detenidas- y se fortalezca la democracia, como afirmaba Dewey, no enseñándola, sino por medio de unas prácticas educativas creadoras de mayor justicia social.

\section{Referencias}

Barreiro, J. (1986). Educación Popular y proceso de concientización. México, Siglo XXI.

Beltrán, J. (2004). Introducción. Nada es inevitable: un inventario de Raymond Williams para la larga revolución. In J. McIlroy \& S. Westwood (Eds.). En la frontera. Raymond Williams en la educación y formación de personas adultas (pp. 5-22). Barcelona: Diálogos.

Besalú, X. (2010). Pedagogía sin complejos. Barcelona: Diálogos.

Cole, J. (2008). Raymond Williams and education - a slow reach again for control. The encyclopedia of pedagogy and informal education. Recuperado el 12 de diciembre de 2020 de https://infed.org/mobi/raymond-williams-and-education-a-slow-reach-again-for-control/.

Dewey, J. ([1916] 1995). Democracia y Educación. Madrid: Morata.

Diaz Salazar, R. (1991). Elproyecto de Gramsci. Barcelona: Anthropos.

Finger, M. y Asún, J. M. (2001). Adult Education at the Crossroad. Learning the Way Out. Leicester: NIACE.

Freire, P. (1984). La importancia de leer y el proceso de liberación. Madrid: Siglo XXI.

Freire, P. (1985). Pedagogía del Oprimido. Madrid: Siglo XXI.

Freire, P. (1986). La Educación como práctica de la libertad. Madrid: Siglo XXI.

Freire, P. (1990). La naturaleza política de la educación. Poder, educación y liberación. Barcelona: Paidós.

Freire, P. (1997). Professora sim, tía não. São Paulo: Olho dágua.

Gelpi, E. (2004). Trabajo Futuro. La formación como proyecto político. Xàtiva: Edicions del CREC.

Geertz, C. (1987). La interpretación de las culturas. Barcelona: Gedisa.

Gramsci, A. (1974). Antología. Madrid: Siglo XXI.

Hooks, B. (2003). Bell Hooks parla de Paulo Freire: l'home, l'obra. In P. McLaren \& P. Leonard (Eds.), Paulo Freire. Un encontre crític. (pp. 193-202). Xàtiva: Edicions del CREC.

Inglis, T. (1997). Empowerment and Emancipation. Adult Education Quaterly, 48(1), pp. 3-18. doi: $10.1177 / 074171369704800102$.

Kirkwood, G., \& Kirkwood, C. (2007). Educación de personas adultas viva. Freire en Escocia. Barcelona: Diálogos.

McIlroy, J. (1993). Border Country: Raymond Williams in adult education. In J. Mcllroy \& S. Westwood (Eds.), Border Country. Raymond Williams in adult education. (pp. 269-323). Leicester: NIACE

Morgan, W. J. (1996). Antonio Gramsci and Raymond Williams: workers, intellectuals, and adult education. Convergence, XXIX(1), pp. 61-74.

Osowski, C. I. (2015). Cultura. In D. Streck, E. Redin \& J. Zitkoski (Orgs.), Diccionario Paulo Freire (pp. 126-128). Buenos Aires: CLACSO.

Osowski, C. I. (2015). Cultura del Silencio. In D. Streck, E. Redin \& J. Zitkoski (Orgs.), Diccionario Paulo Freire (pp. 129-131). Buenos Aires: CLACSO.

Smith, D. (2008). Raymond Williams. A warrior's tale. Londres: Parthian.

Williams, R. (1959). The press and popular education. In J. McIlroy \& S. Westwood (Eds.) (1993), Border Country. Raymond Williams in adult education. (pp. 121-126). Leicester: NIACE

Williams, R. (1960). Culture and Society. Londres: Chatto and Windus.

Williams, R. (1961). An open letter to WEA tutors. In J. Mcllroy \& S. Westwood (Eds.) (1993), Border Country. Raymond Williams in adult education. (pp. 222-224). Leicester: NIACE

Williams, R. (1977). Marxism and literature. Oxford: Oxford University Press.

Williams, R. (1965). The Long Revolution. Londres: Pelican Books.

Williams, R. (1985). Keywords. A vocabulary of Culture and Society. Nueva York: Oxford University Press 
Williams, R. ([1960] 2013). Border country. Llandibie: Library of Wales.

Woolf, V. ([1929] 2019). Um quarto que seja seu. Lisboa: Nova Vega. 